\title{
European Patients' Rights to Be Protected Against Counterfeit Medicines
}

\author{
Cristina-Luiza ERIMIA \\ Ovidius University of Constanta, Faculty of Pharmacy, Constanta, Romania \\ Rodica SîRBU \\ Ovidius University of Constanta, Faculty of Pharmacy, Constanta, Romania
}

Radu George CAZACINCU

Ovidius University of Constanta, Faculty of Pharmacy, Constanta, Romania

Emin CADAR

UMF Carol Davila Bucharest, Faculty of Pharmacy, Bucharest, Romania

Aneta TOMESCU

Ovidius University of Constanta, Faculty of Medicine, Constanta, Romania

Stelian PARIS

Ovidius University of Constanta, Faculty of Pharmacy, Constanta, Romania

\begin{abstract}
Because the falsification of medicines is a global problem, requires increased and effective international coordination and cooperation to ensure the effectiveness of the strategies to combat counterfeiting, especially in relation to the sale of such products on the Internet. In the context of people's health and life rank foremost among the values and interests protected by the TFEU, this article examines the evolution of the legislative process regulating the internal market for medicinal products in order to ensure a high level of protection of public health against falsified medicines and to present the legislative initiatives that have been taken at EU level taking account of new risk profiles, measures meant to ensure, at the same time, the functioning of the internal market of medicinal products. However, this article aims to address consumers' right to have access to safe, effective, quality and innovative medicinal products as a right of the European patient. Ensuring the free movement of medicinal products on the EU market must not violate or restrict this fundamental right of the patient. The threat that falsified medicines pose to public health is also recognized by the World Health Organization (WHO), which has established the International Medical Products Anti-Counterfeiting Taskforce ("IMPACT"). IMPACT has developed the Principles and Elements for National Legislation against Counterfeit Medical Products, which were endorsed by the IMPACT General Meeting in Lisbon on 12 December 2007.
\end{abstract}

Keywords: patient rights, European legislation, the European Union, counterfeit medicinal products, public health, legislative initiatives, internal market, legal supply chain

\section{Introduction}

To reduce the disparities in the field of medicinal products for human use, between certain national provisions, which directly affected the functioning of the internal market, was necessary to draw near the relevant laws, establishing rules for 
monitoring medicinal products and specifying the obligations of the competent authorities of the Member States to ensure compliance with the legal requirements.

Considering its importance for health services, the pharmaceutical sector is subject to strict regulations. Although the main objective of rules governing the production, distribution and use of medicinal products must be to safeguard public health, however, the means by which this goal is achieved, should not prevent the development of the pharmaceutical industry or of the trade in medicinal products in the European Union. In this context, the existing regulatory framework in this sector should not include unnecessary regulatory constraints that restrict and limit competition.

Overseeing the rules regulating and governing the freedom of competition on the pharmaceutical market and the direct and clear intervention if violations of the regulatory framework are found guarantees the existence of a competitive environment in the pharmaceutical sector in the European Union, the complex mechanisms of the pharmaceutical sector being subject to constant and careful analysis both at the level of the European Commission and of the Competition Council.

\section{Theory}

The pharmaceutical sector is vital to the health of European citizens, who must have access to innovative, safe and affordable medicinal products. In terms of regulation, the EU level concerns in terms of competition in the pharmaceutical market pay particular attention to the rules on authorization and marketing, on pricing and reimbursement of medicinal products and to those relating to patents.

When examining the compatibility with Community law of the conditions for the retail supply of medicinal products, the Court of Justice recognized the specific nature of medicinal products, whose therapeutic effects distinguish them substantially from other goods. The Court also stated that the health and life of humans rank foremost among the values and interests protected by the TFEU and that Member States are responsible for deciding on the level of public health protection they wish to provide and the measures to be implemented to achieve this level [1].

Directive 2001/83/EC [2], has been an important step in achieving the objective of free movement of medicines. On average, consumers do not have access to generic medicines earlier than seven months after the date on which innovative medicines have lost exclusivity. This is due, in part, to pharmaceutical companies that use various techniques to extend the commercial life cycle of their products. When the original products compete with generic medicines, prices go down and become accessible to a larger number of patients. In some cases, prices may decrease considerably.

Given the experience, especially by the Committee for Proprietary Medicinal Products, since the adoption of the Community code relating to medicinal products for human use additional measures have been necessary in order to cancel any remaining barriers to the free movement of patented drugs.

In 2005 came into force significant changes in the pharmaceutical regulatory framework, which had the objective of facilitating the market entry of generic medicines [3], for example, the introduction of so-called Bolar provisions [4].

Any action by public authorities in the pharmaceutical sector should aim at creating a competitive environment to ensure the access to medicinal products for European citizens to innovative, safe and affordable medicinal products, without unnecessary delay. In this respect, both competition law enforcement and regulatory measures can improve market performance for the benefit of consumers and should be considered in this regard.

To facilitate the movement of medicinal products and to prevent the duplication of controls from one Member State to another, the minimum requirements for the manufacture and imports from third countries were established, as well as the conditions for granting their authorization.

Because the new protection periods were applied for the innovative product for which authorization was applied for and approved after these rules became effective in 2005, some new rules - namely the new harmonized rules on data and market exclusivity, basically entered into force only in 2013.

Regarding medication, when necessary information to protect public health is already available to the competent authorities of the Member State of destination as a result of first placing on the market of a product in that Member State, a parallel imported product is subject to licenses granted on the basis of a proportionally "simplified" procedure (as opposed to a procedure for granting marketing authorization), if the imported product has been granted a marketing authorization in the Member State of origin and whether the imported product is essentially similar to a product which has received marketing authorization in the Member State of destination. 


\section{Results and Discussions}

The parallel trade in products is a legal form of trade on the internal market. It is "parallel” as it involves products that are essentially similar to products marketed through the sales networks of original producers or suppliers, but which takes place outside and often parallel to those networks.

Parallel trade is a result of differences in prices between pharmaceutical products [5], for example, when Member States establish or otherwise control the price of products sold on their markets. In principle, parallel trade creates healthy competition and price decreases for consumers and is a direct consequence of the development of the internal market which guarantees the free movement of goods.

Although the safety and the first marketing of medicines are regulated by EU law, the principles of legality of parallel trade in these products have been established as a result of decisions of the Court under the provisions of the Treaty on the free movement of goods [6].

In an attempt to balance the rights of parallel traders and the need to maintain public interest objectives such as public health, the Commission has introduced guidelines on parallel imports in the Commission Communication on parallel imports of proprietary medicinal products for which marketing authorizations have already been granted (2003) [7].

In addition, we must distinguish between parallel trade and reimport. For example, in the case of pharmaceutical products, re-importation designates transactions through which are imported medicinal products from a Member State in which they are authorized, after having been previously obtained by a pharmacy in another Member State from a wholesaler in the Member State of import. In this regard, the Court held that a product manufactured in a Member State which is exported and then reimported into the concerned Member State is an imported product in the same way as a product manufactured in another Member State [8]. The Court noted, however, that these findings do not apply if it is found that such products were exported solely for the purpose of re-importation in order to avoid legislation such as that at issue [9].

The threat that falsified medicines pose to public health is a global problem and requires increased and effective international coordination and cooperation to ensure the effectiveness of strategies to combat counterfeiting, especially in relation to the sale of such products on the Internet. Taking account of new risk profiles, legislative initiatives which have been taken at EU level include measures to ensure, at the same time, the internal market of medicines.

An impact assessment conducted in 2008 by the European Commission [10] brought before the authorities alarming elements regarding falsified medicinal products entering the legal supply chain. The analysis has highlighted the increasing number of falsified medicines seized in customs (2.7 million in 2006 to 2.5 million in 2007, representing an increase of $384 \%$ compared to 2005 [11]), the counterfeiting with fatal effects of medicines for serious diseases (heart, cancer) and the introduction to the legal supply chain of fake drugs, including online purchase.

The European Commission estimated that annually are sold to Europe, through legal distribution circuit, 1.5 million boxes of counterfeit medicinal products. The fact that their volume increases on average by $10-20 \%$ per year is even more worrying. With a growth rate of $10 \%$, the number of boxes of falsified medicines in the legal distribution circuit could reach 42 million by 2020 . According to other, more pessimistic estimates, the growth rate is $30 \%$, which would bring this number to 192 million.

Past experience shows that no falsified medicines reach patients only through illegal means, but also via the legal supply chain. This poses a particular threat to public health and can lead to the distrust of patients, including in the legal supply chain. To respond to this increasing threat, Directive 2001/83/EC had to be changed.

Considering all these alarming aspects, the European Parliament and the Council adopted Directive 2011/62 /EU on the prevention of the entry into the legal supply chain of falsified medicinal products [12].

As the stated aim of the Directive is to protect public health, it provides the legal basis for which the counterfeiting of medicinal products is a criminal act which deprives patients of safe and quality medical treatment.

The measures of the Directive to include the mandatory application on the packaging of medicinal products of safety features [13], the increased controls and inspections of factories producing active pharmaceutical substances [14], increasing the strictness of distributor records, the obligation of producers and distributors to report medicinal products presumed fake, and the centralized regulation of online pharmacies. 
However, the distribution network of medicinal products is increasingly complex and involves many players which are not necessarily wholesale distributors as referred to in that Directive. This includes not only wholesale distributors, whether or not they physically handle drugs but also intermediaries who are involved in the sale or purchase of medicinal products without selling or purchasing those products themselves, and without owning and physically handling the medication.

The illegal sale of medicinal products to the public via the Internet constitutes a serious threat to public health because in this way counterfeit drugs may reach the public. It was therefore necessary to address this threat in Directive 2011/62/EU.

In this regard, account was taken of the fact that specific conditions for the supply of medicinal products to the public have not been harmonized at EU level and, therefore, Member States may impose conditions for supplying medicinal products to the public within the Treaty on European Union (TFEU).

The Court of Justice of the European Union, analyzing the compatibility with Community law of the conditions for the supply of retail drugs, held that the Member States are responsible for deciding on the level of public health protection they wish to provide and means to be implemented to achieve this level [15].

The Court also stated [16] that Member States should have discretion as regards the supply of medicinal products to the public on their territory. Given the particular risks to public health and the power given to Member States to determine the level of protection of public health, the Court has recognized that Member States may, in principle, restrict the retail sale of medicinal al products to pharmacies only.

Without prejudice to national legislation prohibiting the remote offer for sale to the public of medicinal products subject to medical prescription via the Internet [17], the Member States must ensure that products are offered for sale remotely to the public by means of information society services as defined in Directive 98/34/EC [18].

So that the functioning of the internal market not be unduly restricted, but also for public health protection, for the retail supply of medicinal products sold online, the Directive 2011/62/EU proposes the creation of a common logo that can be recognized throughout the Union and allowing the identification oft he Member State of establishment of the person offering the medicinal products for remote sale to the public. The logo shall be clearly displayed on the Internet site offering the medicinal products for remote sale to the public.

To prevent drugs that are suspected to present a danger to health from reaching the patient, Member States use a system that includes the receipt and handling of notifications of suspected falsified medicinal products, as well as suspected quality defects of medicinal products. If it is suspected that falsified medicinal products have reached patients, urgent public announcements are made within 24 hours to recover these products from the patients. Such notices shall contain sufficient information on the suspected quality defect or falsification and the risks involved.

Enlightening in this respect is the case of Pegasys, which we will present in the following. In November 2013, the Police and the National Agency for Medicines and Medical Devices (MAMD) started an investigation after three pharmacies in the country were found counterfeit syringes with serum hepatitis B and C.

The Syringes with counterfeit hepatitis serum, on which the investigation was initiated, were found in two pharmacies in Pitesti and in one of lalomita County. The investigation was initiated as a result of complaints received from patients.

The drug manufacturer, Roche Romania SRL, informed the National Agency for Medicines and Medical Devices (NAMMD) in September 2013 on the identification in Germany by the quality department of F. Hoffmann-La Roche, Basel Ltd. of a box of counterfeit Pegasys $180 \mathrm{mg} / 0.5 \mathrm{ml}$. After this information, constant communication with NAMMD continued related to occurrence of suspected counterfeit boxes in Romania. As well, Roche Romania SRL has shown that by November there were no reported cases of counterfeit suspicions of possible penetration in Romania.

After dozens of boxes of counterfeit Pegasys were released in November on prescription in pharmacies in several counties and irregularities were noticed by several people with hepatitis, the forgery came to the attention of the national authorities.

In the context of the investigation started, the Ministry of Health recommended that patients using the product Pegasys 180 $\mu \mathrm{g} / 0.5 \mathrm{ml}$ solution for injection in pre-filled syringe, when buying it in the last two weeks, to immediately contact the treating physician to determine the appropriate therapeutic management.

In this case, the counterfeiting of a drug for a serious chronic disease, we can speak of a criminal act because for patients with hepatitis $B$ and $C$, interferon vials mean life expectancy. Counterfeit drugs could endanger patient response to 
treatment and even his/her life. The interest in counterfeiting this medicinal product is obviously economic because one vial has an average price of $750 \mathrm{RON}$, the entire sum being paid by the state through national health programs. Therefore, the investigation of the national health authority was doubled by that of the Organized Crime.

\section{Conclusion}

Fighting the penetration of falsified medicinal products in the legal supply chain without hampering the functioning of the internal market of medicinal products is a goal that can not be sufficiently achieved by the Member States and can therefore be better achieved by the Community.

When referring to the implications of a falsification of on public health, we must consider both the specific characteristics of the products in question, and the severity of the conditions intended to be treated with such medicinal products. Another aspect to be taken into consideration when introducing counterfeit medicines into the legal distribution chain is the price of counterfeit medicines. Counterfeiting of medicines for serious chronic diseases, for example, lead to reimbursement by the state of the full price of the medicinal product in question and, in addition, to tax evasion produced by the people introducing the forgeries to the legal distribution network, which endangers the lives of patients, by the lack of the necessary treatment.

Counterfeit drugs are illegal in terms of EU pharmaceutical legislation as they do not comply with EU rules on medicinal products. They pose a major threat to European patients and European industry and the public and stakeholders are deeply concerned about the steady increase of these products detected in the European Union in recent years.

Another concern is the fact that the risk profile has changed. The number of falsifications of innovative and life-saving medicines is increasing.

Even if you the exact number of existing or future cases is unknown, there is a noticeable trend clearly threatening the high level of public health protection in the European Union. We believe that this trend can have disastrous consequences for consumer patient confidence in the pharmaceutical industry and the policy makers.

The assessment of policy options, starting from a baseline of "non-action" on falsified medicinal products entering the legal distribution chain and estimates based on existing data, which are limited, were revealed the direct and indirect costs to society of non action, which could reach, depending on the scenario, between 9.5 billion and 116 billion by 2020 .

The European Commission compared the costs of non-action costs for achieving the chosen policy options, namely the elimination, by all means, of the risk of falsified medicines entering the legal supply chain, and estimated the costs which will be incurred by 2020 by all actors involved in the distribution of medicines on the internal market.

Unfortunately, the costs the patients consumers of these counterfeit medicinal products have to bear can not be estimated, the danger that they have on human health and life can not be quantified.

\section{References}

[1] See Case C-192/01 Commission/Denmark, Rec. 2003, p. I-9693, point 46 and Cauza C-24/00 Commission/France, Rec. 2004, p. I-1277, point 53.

[2] Directive 2001/83/EC of the European Parliament and of the Council of 6 November 2001 on the Community code relating to medicinal products for human use, published in the Official Journal of the European Union $L 311$, 28.11.2001, p. 67

[3] See, for example, Directive 2004/27/EC of the European Parliament and of the Council of 31 March 2004 amending Directive 2001/83/EC on the Community code relating to medicinal products for human use, published in the Official Journal of the European Union L 136 of 30.4.2004.

[4] Article 10 paragraph (6) of Directive 2001/83/EC modified by Directive 2004/27/EC: this provision had to be transposed by Member States by 31 October 2005. Prior to the introduction of the Bolar provision in the EU regulatory framework, the development of the patent before its expiry was not regulated at EU level. Consequently, generic manufacturers have developed products for the development and testing conducted in countries where the basic patent had expired or where such protection does not exist, outside the EU, in European countries where there is a Bolar type provision or EU Member States where experimental work was allowed in certain cases (cf. section B.2.2.1 of the technical annex). 
[5] Case C-201/94 Smith \& Nephew, Rec. 1996, p. I-5819..

[6] Treaty on the Functioning of the European Union (consolidated version), published in the Official Journal of the European Union (OJEU) C 326 of 26 December 2012, Article 34.

[7] COM(2003) 839 final: http://eur-lex.europa.eu/LexUriServ/site/en/com/2003/com2003_0839en01.pdf.

[8] Case C-322/01 Deutscher Apothekerwerband, Rec. 2003, p. I-14887, point 127. See in this respect Case 229/83 Leclerc et al., Rec. 1985, p. 1, point 26, and case C-240/95 Schmit, Rec. 1996, p. I-3179, point 10.

[9] Case C-322/01 Deutscher Apothekerwerband, Rec. 2003, p. I-14887, point 129.

[10] Commission of the European Communities, Commission Staff Working Document Accompanying document to the Proposal for a Directive of the European Parliament and of the Council amending Directive 2001/83/EC as regards the prevention of the entry into the legal supply chain of medicinal products which are falsified in relation to their identity, history or source, Impact Assessment, SEC(2008) 2674, Brussels, 10.12.2008.

[11] European Commission, Public consultation in preparation of a legal proposal to combat counterfeit medicines for human use, Key ideas for better protection of patients against the risk of counterfeit medicines, Brussels, 11.03.2008.

[12] Directive 2001/83/EC of the European Parliament and of the Council of 6 November 2001 on the Community code relating to medicinal products for human use, published in the Official Journal of the European Union $L 311$, 28.11.2001, p. 67.

[13] Directive 2011/62/UE, Article 1, Point 8 introducing Article 47a.

[14] Commission Delegated Regulation (EU) No 1252/2014 of 28 May 2014 supplementing Directive 2001/83/EC of the European Parliament and of the Council with regard to principles and guidelines of good manufacturing practice for active substances for medicinal products for human use, publicat în Jurnalul Oficial al Uniunii Europene L 337, 25.11.2014

[15] See Case C-270/02 Commission /Italiy, Rec. 2004, p. 1559

[16] Case C-322/01 Deutscher Apothekerverband eV, Rec. 2003 I-14887.

[17] See Case C-319/05 Commission/Germany, Rep. 2007, p. I-9811

[18] Directive 98/34/EC of the European Parliament and of the Council of 22 June 1998 laying down a procedure for the provision of information in the field of technical standards and regulations and of rules on Information Society services, published in the Official Journal of the European Union L 204, 21.7.1998, p. 37. 